\title{
Features of the impact of digital technologies on young people
}

\author{
Vlad Dmitriev, * and Galina Zvezdina
}

Don State Technical University, 344003, Rostov-on-Don, Russia

\begin{abstract}
The study of the psychological characteristics of gamers is an actual task for scientists associated with the rapid spread of gadgets, an increase in the number of gamers and the number of people with problems with addictive behavior from video games. The aim of this work is to study personality traits in people with different levels of computer gaming activity. The study involved 162 people aged 18 to 30 , of whom 36 were women. The respondents were offered an electronic questionnaire, which included the Leonhard-Smishek Characterological Questionnaire, the adapted Chen Internet addiction scale, the Big Five questionnaire, Osgood's semantic differential, and the Behavioral self-regulation questionnaire. Data analysis was carried out using the Pearson linear correlation coefficient and the Mann-Whitney test. Calculations were performed in IBM SPSS Statistics. The results of people with a high level of dependent behavior are characterized by ambivalence: a low level of self-control and responsibility is combined with the presence of pedantry; a subjective assessment of oneself as a kinder, unselfish and honest person is adjacent to the characterization of oneself as more hostile and callous. The results obtained allowed us to make an assumption about the possibility of dividing the group of addicts into two subgroups: open, extroverted, hyperthymic, talkative people with a high rate of withdrawal syndrome and tolerance; people are introverted, closed, silent, with intrapersonal problems and health problems.
\end{abstract}

\section{Introduction}

The computer games industry has become one of the largest entertainment industries, and this has happened not only due to technological progress and the growth in the quality of games, but also thanks to new psychological and marketing mechanisms used by publishers to attract as many players as possible for as long as possible.

The mechanics and quality of the games now allow you to watch with interest both the competitions and the usual gameplay. Graphics, plot, balance - all this makes games a real sport with a growing audience.

The relevance of research in the field and the consequences of the widespread distribution of video games is evidenced by the interest of international organizations in this issue: the American Society of Psychiatrists included the concept of Internet gaming

\footnotetext{
*Corresponding author:79185137266@ya.ru
} 
disorder in the fifth edition of the Manual on Mental Disorders (DSM-5), and the World Health Organization in 2018 introduced a similar term - gaming disorder.

Many researchers find a connection between addictive behavior and some personality traits and character. At the same time, such connections remain ambiguous, often, the data of some works contradict the data of others. For example, in some works, the following types of relationships between personality traits and play activity and addictive behavior were noted

- straight line with introversion factor [1,2]

- negative with the level of self-control, while no association was found in other studies $[3,4,5]$

- positive with aggressiveness [5,6,7]

- connection with the level of awareness, difficulty in organizing your life [8,9]

- Many studies have found a link with neuroticism [10,11] and escapism [12,13], the desire for vocation [14] and socialization $[15,16]$.

The theoretical basis of the study is the work of domestic (Voiskunsky A.E., Omelchenko N.V., Bogacheva N.V., Dobrovidova N.A., Shmelev A.G., Serkin V.P., Stepantseva O.A., Usova E.B.) and foreign authors (Griffiths M.D., Kim M.G., Chen Y.F., Kiraly O.), dedicated function phenomenon in general, and depending on the Internet and computer games in particular.

\section{Methods}

The paper compares the psychological characteristics of persons aged 18-30 years with different levels of computer gaming activity and a tendency to addictive behavior.

The aim of this work is to study personality traits in people with different levels of computer gaming activity.

The object of the study was young people aged 18 to 30 years. The total number of respondents is 162 people, of whom 36 are women, 126 are men, with an average age of 26.9 years. The social status is heterogeneous - 69 people work full time, 16 people do not have a permanent job, 77 people combine work and study at a university.

The subject of the research is the personality traits of young people with different levels of addictive behavior from computer games.

Hypotheses to be tested:

1. People with different levels of addiction to computer games have differences in the severity of some personal characteristics;

2. The level of addictive behavior from computer games can be associated with the personal characteristics of the respondents;

3. Persons with a high level of addiction to computer games may be characterized by a reduced level of self-discipline, self-control and openness.

To test the hypotheses, a questionnaire was compiled, consisting of the following methods:

1. Leonhard-Smishek Characterological Questionnaire - a personality questionnaire designed to diagnose the type of personality accentuation.

2. Chen's Adapted Internet Addiction Scale is a modification of the most modern questionnaire that allows you to establish the degree of addiction. [17]

3. Methodology "Personal Semantic Differential". The technique was developed on the basis of three factors of the semantic differential of C. Osgood.

4. Questionnaire "Style of self-regulation of behavior" by V.I. Morosanova. The technique allows diagnosing the development of individual self-regulation, building its individual profile. [18]

5. The Big Five, a questionnaire developed by R. McCrae and P. Costa. 
Data collection was carried out in the form of filling out a questionnaire in electronic form using the Google Forms service.

The study involved 162 people. The respondents were divided into groups, in accordance with the received score for the modification of Chen's method. Based on the description of the methodology, the group of respondents with a total score above 58 and no more than 64 is a group with a stable tendency to develop addictive behavior. Comparing this group with the group of addicts using the Mann-Whitney test for all scales of methods, it was decided to combine this group with the group of addicts, since there were no significant differences.

In this regard, further research was carried out on the example of three groups:

1. Group with the minimum risk of addictive behavior, the total number of respondents - 74 people, including 22 women, 52 men, average age - 26.09 years, average total score 35.55 .

2. The group of respondents with a tendency to addictive behavior - 67 people, including 9 women, 58 men, average age 27.46 years, average total score 50.46 .

3. The group of respondents with a developed propensity to develop addictive behavior and a stable pattern of addictive behavior - 21 people, including 5 women, 16 men, average age -25.93 years, average total score 74 .

\section{Results}

For convenience, we will designate the group with the minimum risk of addiction as "Independent", the group of respondents prone to the emergence of addictive behavior "Inclined", and the group of respondents with a developed addiction and a stable pattern of addictive behavior will be designated as "Addicts". Let's move on to describing the results.

On average, the increase in points on the five scales of the Chen questionnaire was 3.03 points, the largest difference in indicators was recorded on the scale of "Intrapersonal problems and health problems" between the "Dependent" and "Inclined" groups. Each group scored the highest number of points on the Intrapersonal and Health Problems scale, and the lowest on the Tolerance scale.

Table 1. Average group values according to Chen's method scales

\begin{tabular}{|l|l|l|l|l|l|l|}
\hline \multirow{2}{*}{ Scale } & \multicolumn{2}{|c|}{ Addicted } & \multicolumn{2}{c|}{ Inclined } & \multicolumn{2}{c|}{ Independent } \\
\cline { 2 - 7 } & $\begin{array}{l}\text { Group } \\
\text { score }\end{array}$ & $\begin{array}{l}\text { Guideline } \\
\text { values }\end{array}$ & $\begin{array}{l}\text { Group } \\
\text { score }\end{array}$ & $\begin{array}{l}\text { Guideline } \\
\text { values }\end{array}$ & Group score & $\begin{array}{l}\text { Guideline } \\
\text { values }\end{array}$ \\
\hline $\begin{array}{l}\text { Compulsive } \\
\text { symptoms }\end{array}$ & 11.67 & 13.5 & 8.25 & 9.789 & 6.18 & 7.5 \\
\hline $\begin{array}{l}\text { Withdrawal } \\
\text { symptoms }\end{array}$ & 12.67 & 17.5 & 10.01 & 11.526 & 7.22 & 7.875 \\
\hline Tolerance & 9.33 & 11.667 & 7.03 & 7.895 & 5.62 & 6.5 \\
\hline $\begin{array}{l}\text { Intrapersonal } \\
\text { and health } \\
\text { problems }\end{array}$ & 17.71 & 17.167 & 12.00 & 11.895 & 8.99 & 8.875 \\
\hline $\begin{array}{l}\text { Time } \\
\text { management }\end{array}$ & 14.48 & 15.834 & 11.03 & 10.632 & 7.55 & 7.25 \\
\hline Key symptoms & 33.67 & 42.667 & 25.30 & 29.474 & 19.01 & 21.875 \\
\hline $\begin{array}{l}\text { Addiction } \\
\text { problems }\end{array}$ & 32.19 & 33.0 & 23.03 & 22.842 & 16.54 & 16.125 \\
\hline Overall score & 65.86 & $>65$ & 48.33 & $43-64$ & 35.55 & $27-42$ \\
\hline
\end{tabular}


According to the questionnaire "Style of self-regulation of behavior", the group "Independent" has on average a higher score on all scales, with the exception of the scales "Planning" and "Independence". The results of all groups are within the normal range, with the exception of the average result of the "Addicts" group on the "Programming" scale: the respondents in this group scored 4.67 points, while the lower limit of the norm is at around 5 points.

Leonhard-Smishek Characterological Questionnaire did not reveal the presence of signs of accentuations. It should be noted that the "Inclined" group is the only one in which the presence of a sign of hyperthymia is manifested in the respondents: on average, the respondents of this group scored 12.36 points on this scale, which is the lower limit, when approaching which we can talk about the presence of signs in the subjects accentuation. Also, the "Addicts" group was the only one who showed an average result on the "Cyclothymic" scale - 15.29 points - sufficient to indicate that the respondents in this group have a tendency to accentuation.

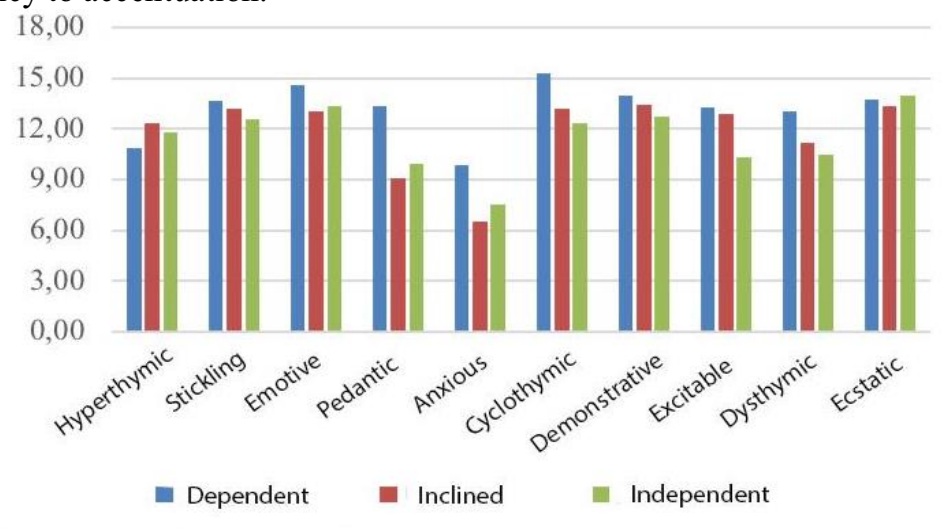

Fig. 1. Average group values of Leonhard-Smishek Characterological Questionnaire

On the "Big Five" test on all scales the groups showed results corresponding to the average values of the indicators. Despite the well-established stereotype in society about the gamer as a closed and not sociable person, the "Addicts" group showed the highest results on the "Extraversion-Introversion" scale. Also, this group showed the highest result on the scale of "Emotional stability". The result of this category on the "Self-controlImpulsiveness" scale is the lowest among the other groups: the "Addicts" group scored on average 42.43 points on this parameter, this means that the "Addicts" group is somewhat more impulsive than other groups. These results correlate with the results of the questionnaire "Behavioral self-regulation style".

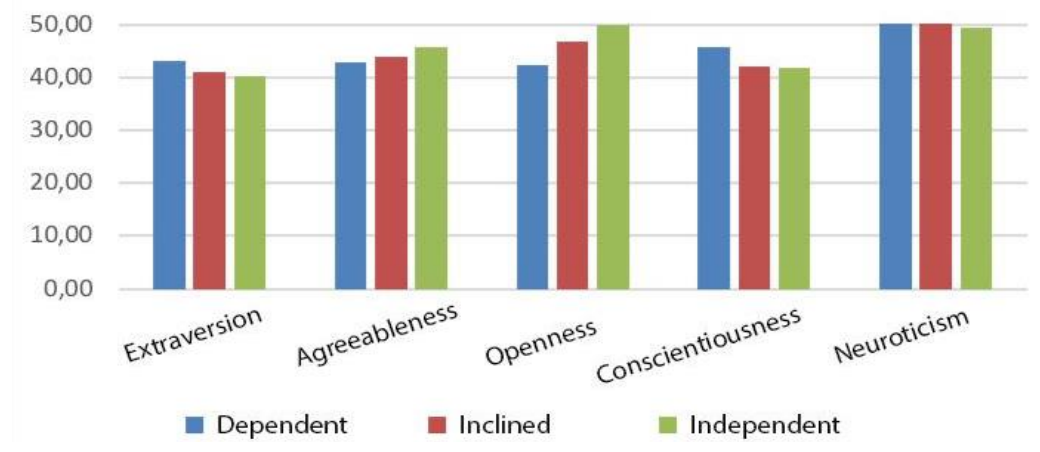

Fig. 2. Average group values questionnaire "Big five" 
Consider the values obtained using the Personal Semantic Differential questionnaire. The profile shows significant differences in the ratings of the "Dependent" group from the "Independent" group on such scales as "Irresponsible-Conscientious", "Kind-Selfish", "Callous-Responsive", "Hectic-Calm", "Honest-Insincere" and "Dependent-Independent". The strongest average score differs in the scales "Fair-Unfair", "Hectic-Calm", "Hostilefriendly", "Honest-insincere", "Independent-Independent".

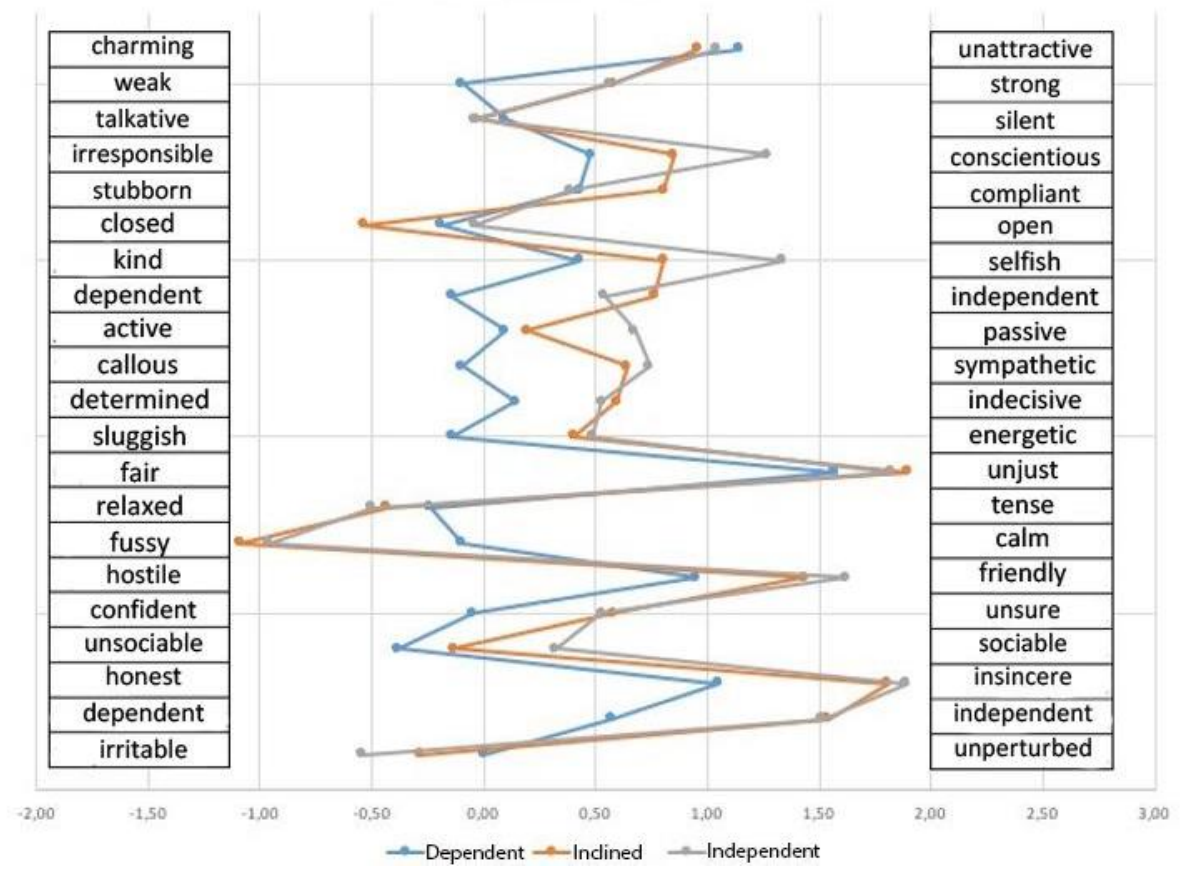

Fig. 3. Average group values questionnaire "Personal semantic differential"

Further statistical analysis of the data was carried out using the Pearson linear correlation coefficient and the Mann-Whitney test (pairwise comparison of the mean levels of the groups). Calculations were performed in IBM SPSS Statistics (version 23.0).

The Mann-Whitney test was used to compare the average levels of quantitative indicators in the groups for all methods.

When pairwise comparison of the results of the groups using the method "Behavioral self-regulation style", differences were revealed between the "Dependent" and "Independent" groups on the scales "Programming" and "General self-control" - the "Addicts" group has a lower average score on these scales. This may indicate a poor ability to think through their actions to achieve a goal and an impulsive style of behavior.

Differences between the groups "Inclined" and "Independent" were found on the scale "Evaluating the results" - "Inclined" showed a lower result. This difference can characterize the representatives of the "Inclined" group as the owners of a lower or less adequate level of assessment of the results of their own activities. This can lead to instability of performance results when external conditions change. No significant differences were found between the groups "Inclined" and "Dependent".

Table 2. Pairwise comparison of the results of the groups according to the method "Style of selfregulation of behavior" using the Mann-Whitney test

\begin{tabular}{|l|l|l|l|l|l|l|}
\hline \multirow{2}{*}{ Scale } & \multicolumn{3}{|c|}{ Average values } & \multicolumn{3}{c|}{ Significance level $(\rho)$} \\
\cline { 2 - 6 } & Addicted & Inclined & Independent & Dependent- & Inclined- & Dependent- \\
\hline
\end{tabular}




\begin{tabular}{|l|l|l|l|l|l|l|}
\hline & & & & independent & independent & inclined \\
\hline Planning & $5.24 \pm 1.92$ & $5.81 \pm 2.08$ & $5.69 \pm 1.94$ & 0.374 & 0.710 & 0.239 \\
\hline Modeling & $5.29 \pm 1.85$ & $5.31 \pm 1.95$ & $5.84 \pm 1.78$ & 0.263 & 0.131 & 0.903 \\
\hline Programming & $4.67 \pm 2.2$ & $5.63 \pm 1.75$ & $5.97 \pm 1.58$ & 0.008 & 0.198 & 0.055 \\
\hline $\begin{array}{l}\text { Evaluating } \\
\text { Results }\end{array}$ & $5.76 \pm 1.51$ & $5.75 \pm 1.36$ & $6.32 \pm 1.33$ & 0.150 & 0.007 & 0.751 \\
\hline Flexibility & $5.81 \pm 2.04$ & $5.64 \pm 1.9$ & $6.11 \pm 1.91$ & 0.537 & 0.149 & 0.750 \\
\hline Independence & $5.95 \pm 2.01$ & $5.88 \pm 2.06$ & $5.36 \pm 2.17$ & 0.267 & 0.168 & 0.849 \\
\hline $\begin{array}{l}\text { General level } \\
\text { of self- } \\
\text { regulation }\end{array}$ & $27.9 \pm 5.73$ & $29.12 \pm 5.32$ & $30.46 \pm 4.73$ & 0.045 & 0.089 & 0.386 \\
\hline
\end{tabular}

By comparing the results of the Big Five questionnaire, we found differences between the Dependent and Independent groups on the Self-Control-Impulsiveness scale. The lower result shown by the "Dependents" group indicates that representatives of this category do not often show volitional personality traits. This difference. as well as the results of the questionnaire "Style of self-regulation of behavior", shows the predominance of impulsivity in their actions, thoughtlessness of behavior, greater "naturalness". It may also indicate a greater tendency to non-compliance with cultural norms and rules accepted in society.

No significant differences were found between other compared pairs.

Table 3. Pairwise comparison of the results of groups according to the The Big Five using the Mann-Whitney test

\begin{tabular}{|l|l|l|l|l|l|l|}
\hline \multirow{2}{*}{ Scale } & \multicolumn{4}{|c|}{ Average values } & \multicolumn{3}{c|}{ Significance level $(\rho)$} \\
\cline { 2 - 7 } & Addicted & Inclined & Independent & $\begin{array}{l}\text { Dependent- } \\
\text { independent }\end{array}$ & $\begin{array}{l}\text { Inclined- } \\
\text { independent }\end{array}$ & $\begin{array}{l}\text { Dependent- } \\
\text { inclined }\end{array}$ \\
\hline $\begin{array}{l}\text { Extraversion- } \\
\text { introversion }\end{array}$ & $43.1 \pm 9.76$ & $40.99 \pm 11.05$ & $40.28 \pm 10.08$ & 0.231 & 0.648 & 0.403 \\
\hline $\begin{array}{l}\text { Attachment- } \\
\text { detachment }\end{array}$ & $42.86 \pm 8.21$ & $44.01 \pm 9.88$ & $45.88 \pm 10.63$ & 0.189 & 0.252 & 0.546 \\
\hline $\begin{array}{l}\text { Self-control- } \\
\text { Impulsivity }\end{array}$ & $42.43 \pm 8.44$ & $46.75 \pm 10.07$ & $49.95 \pm 6.96$ & 0.001 & 0.071 & 0.052 \\
\hline $\begin{array}{l}\text { Extraversion- } \\
\text { introversion }\end{array}$ & $45.9 \pm 11.76$ & $42.09 \pm 12.71$ & $41.88 \pm 9.49$ & 0.157 & 0.811 & 0.140 \\
\hline $\begin{array}{l}\text { Attachment- } \\
\text { detachment }\end{array}$ & $50.38 \pm 7.43$ & $50.3 \pm 7.98$ & $49.41 \pm 7.46$ & 0.993 & 0.610 & 0.646 \\
\hline
\end{tabular}

The questionnaire "Personal semantic differential" is designed to show the subjective attitude of respondents to themselves. For this questionnaire it had revealed the greatest number of differences.

- Significant differences were found between the "Dependents" and "Independent" groups, according to which the "Addicts" rate themselves as more irresponsible, callous, fussy and hostile, as well as kind and honest. The observed contradictions (for example, Kind and Callous, Kind and Hostile) can be explained by fewer real social contacts, due to the greater amount of time spent in the game, and, as a consequence, fewer opportunities to evaluate oneself more objectively in a situation of real interaction with people. The respondents from the "Dependent" group, like the respondents from the "Independent" group, generally assess themselves positively, but have a lower score on this scale.

- Significant differences were found between the Dependent and Inclined groups on the Dependent, Fidgety, and Strength scales. Respondents from the "Addicts" group assess themselves as more independent, but lower results (albeit positive, 0.62 points) on the scale "Strength" indicate the opposite - about a more rare manifestation of volitional personality 
traits, inability to adhere to the accepted model of behavior, insufficient self-control level. This is evidenced by the data obtained using the questionnaires above.

- Between the "Inclined" and "Independent" groups on the "Kind" scale.

We also carried out a statistical analysis of the presence of correlations between various factors using the Spearman test. The study involved a group of "Dependents" in the amount of 21 people.

When analyzing the scales of the Chen questionnaire aimed at studying addiction to computer games, moderate correlations were found between several factors, some of which are repeated.

The factor "Hyperthymic" is positively and moderately associated with the scale "Symptoms of withdrawal" and negatively associated with the scale "Intrapersonal and health problems".

The "Extraversion-Introversion" factor is positively moderately associated with the scale "Withdrawal syndrome", "Tolerance", "Key symptoms".

The Closed-Open factor positively correlates with such scales as Compulsive Symptoms, Withdrawal Syndrome, Key Symptoms, and negatively correlates with the Intrapersonal and Health Problems scale.

The "Talkative-Silent" factor is positively associated with the "Withdrawal Syndrome" scale, and negatively with the "Intrapersonal and Health Problems" scale.

The "Tolerance" scale revealed positive moderate connections with factors such as "Independence", "Demonstrative", "Dependent-Independent", "Unsociable-Sociable",

The Time Management scale is positively moderately associated with the Active-Passive factor.

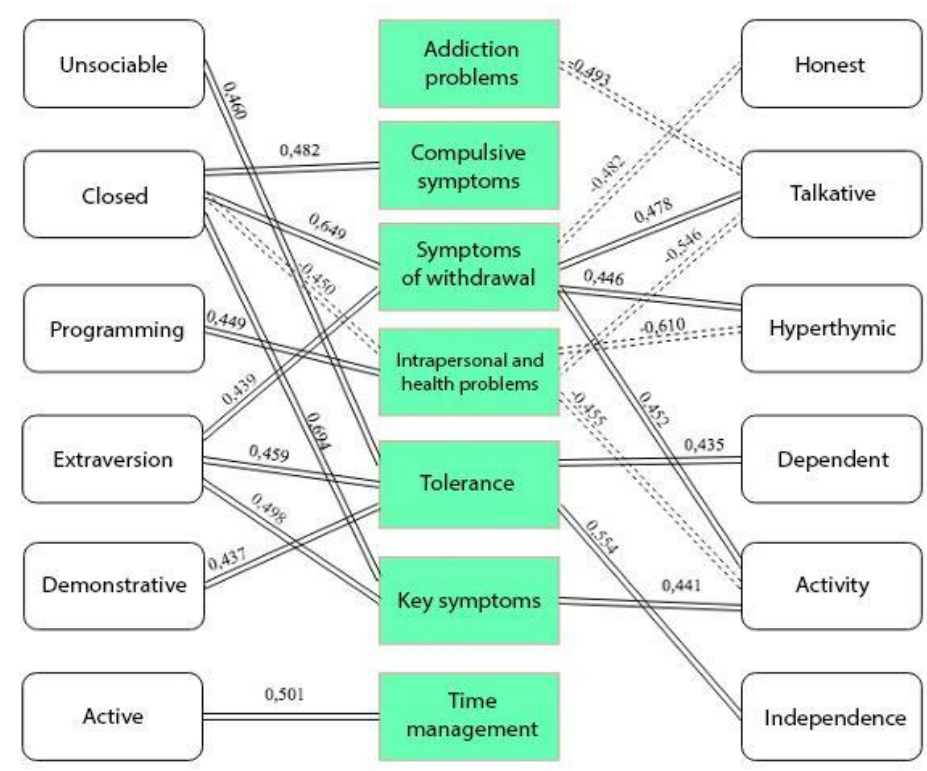

Fig. 4. Correlation pleiad of scales of Chen's questionnaire with scales of methods "Style of selfregulation of behavior", "Leonhard-Smishek Characterological Questionnaire", "Big Five", "Personal semantic differential"

\section{Discussion}


Based on these results, we can say that the psychological characteristics of a person with signs of addictive behavior from computer games are characterized mainly by ambivalence: a low level of self-control and responsibility is combined with the presence of pedantry; a subjective assessment of oneself as a kinder, unselfish and honest person is adjacent to the characterization of oneself as more hostile and callous. Inability or unwillingness to calculate their actions to achieve a certain goal, inadequacy of the assessment of the intermediate results obtained, impulsivity, a low level of self-control in general, lead to imbalances in behavior.

It can be assumed that this ambivalence, on the one hand, shows the inability of the "Addicts" to independently assess their own actions, which is required in real life, and what a computer game provides them, where each player's action has its own assessment, cost, reward. On the other hand, in a computer game, a person is freed from the need to program his future, make long-term plans and prospects - after all, each next step is dictated by the game, and the player must follow this, in which he is helped by his inherent pedantry. It is noteworthy that these same characteristics are characteristic of "inclined" personalities.

Thus, presumably, people with problems in self-control, evaluating themselves and their actions, planning their future, getting into the world of a computer game, are freed from the need to implement them on their own, and therefore their skill in these areas is further reduced. Hence, functioning in real life becomes even more difficult. For this reason, the "Inclined" ones have increased anxiety and fussiness, which prompts them to return to the game again, turning them from "Inclined" to "Addicted".

Based on the correlative constellation, it is possible to single out personal characteristics associated with the symptoms and consequences of addiction to computer games:

- key compulsive symptoms, withdrawal syndrome and tolerance are associated with extraversion / activity, hyperthymicity, demonstrativeness , talkativeness, openness, independence, independence, sociability.

- The presence of social and somatic problems associated with addiction to computer games with introversion, isolation, taciturnity, activity.

The results obtained are similar to the results of some studies, in which a connection was found with self-control, introversion and organization of activities.

The category of "Addicts" can be divided into two groups: open, extroverted, hyperthymic, talkative people with a high rate of withdrawal symptoms and tolerance to games. We assume that in this case, the attachment to computer games is in the nature of a hobby, a hobby. In contrast to this group, there are people who are introverted, closed, taciturn, with intrapersonal problems and health problems. We believe that this particular category of people can be called "truly addicted", since, in our opinion, for them a computer game is not of an entertainment and leisure character, but serves as a means of escape from reality.

These assumptions cannot be proven or refuted in this study, however, thanks to it, it becomes obvious that it is necessary to study the motivational and value-semantic sphere of the personality of people exhibiting addictive behavior from computer games.

\section{Conclusion}

The problem of various types of computer and Internet addictions is one of the newest and most urgent research tasks for psychologists. Taking into account the time of the emergence of the first computer games and the Internet, given the pace of technology development and expansion into everyday life, it can be assumed that the problem of these addictions may soon become global. In this regard, in the West, and more recently in Russia, there is an increase in the number of research works in this area. 
This study is an attempt to compile a psychological portrait of people exhibiting a stable pattern of addictive behavior from computer games, to identify personality traits that accompany the formation of this addiction.

Thanks to the conducted research, it was revealed that:

- individuals who exhibit addictive behavior from computer games differ in a number of parameters both from people who do not exhibit addictive behavior (programming, evaluation of results, pedantry, anxiety, imbalance, cyclothymicity, extraversion), and from people who are prone to addictive behavior from computer games;

- psychological characteristics of a person with signs of addictive behavior from computer games are characterized mainly by ambivalence: a low level of self-control and responsibility is combined with the presence of pedantry; a subjective assessment of oneself as a kinder, unselfish and honest person, side by side with the characterization of oneself as more hostile and callous;

- the presence of key compulsive symptoms, withdrawal syndrome and the emergence of tolerance in people exhibiting a stable pattern of addictive behavior are associated with such personal characteristics as extraversion / activity, hyperthymicity, demonstrativeness, talkativeness, openness, independence, independence, sociability.

- the manifestation of intrapersonal problems and health problems, time management, in people exhibiting a stable pattern of addictive behavior: associated with such personal characteristics as introversion, withdrawal, reticence, and activity.

The hypotheses put forward by us have been confirmed to one degree or another.

The hypothesis that people with different levels of addiction to computer games have differences in the severity of personal characteristics has been fully confirmed;

the hypothesis that there is a connection between the level of addictive behavior towards computer games and some personal characteristics was confirmed;

the hypothesis that people with a high level of addiction to computer games are characterized by a reduced level of self-discipline, self-control and openness was partially confirmed, since, according to the data obtained, the structural components of addiction to computer games correspond to a certain level of independence, openness and activity (key symptoms - extroverted characteristics, whereas intrapersonal and health and time management problems are introverted characteristics).

On the basis of the revealed features you can see the future prospects of research, particularly the study of motivation and value-semantic sphere of the person people showing a steady pattern of addictive behavior on computer games as epywere found correlations that indicate that extraverted and introverted personalities dominated by different components of addiction to computer games.

\section{References}

1. V. González-Bueso, J. Santamaría, D. Fernández, L. Merino, E. Montero, J. Ribas, International Journal of Environmental Research and Public Health 15(4), 668 (2018). doi.org/10.3390/ijerph15040668

2. Ş.I. Şalvarlı, M.D. Griffiths, International Journal of Mental Health and Addiction. (2019) doi.org/10.1007/s11469-019-00081-6

3. D.J. Mills, J.J. Allen, Self-determination theory, internet gaming disorder and the mediating role of self-control (Computers in Human Behavior, 2019) doi.org/10.1016/j.chb.2019.106209

4. E.J. Kim, European psychiatry 23(3), 212-218 (2008). doi.org/10.1016/j.eurpsy.2007.10.010 
5. E. Collins, J. Freeman, Computer human behaviour 29(5), 33-40 (2013) doi.org/10.1016/j.chb.2013.03.002

6. M. Mehroof, M.D. Griffiths, Cyber psychology, Behavior, and Social Networking 13(3), (2010). doi.org/10.1089/cyber.2009.0229

7. Z.I. Brizhak, A.S. Kolenova, A.M. Kukulyar, International Journal of Medicine and Psychology 4(1), 78-84 (2021).

8. S. Cole, J. Hooley, Social Science Computer Review.31(4), (2013) doi.org/10.1177/0894439312475280

9. K. Müller, M. Beutel, B. Egloff, K. Wölfling, European Addiction Research 20(3), (2014). doi.org/10.1159/000355832

10. F. Rehbein, M. Kleimann, T. Mößle, Cyber psychology, Behavior, and Social Networking 13, 269-277 (2010). doi.org/10.1089/cyber.2009.0227

11. C. Wittek, T. Finserås, S. Pallessen, International Journal of Mental Health and Addiction. (2015) doi.org/10.1007/s11469-015-9592-8

12. Z. Demetrovics, R. Urban, K. Nagygyorgy, J. Farkas, D. Zilahy, B. Mervo, A. Reindl, C. Agoston, A. Kertesz, E. Harmath, Behavior Research Methods 43(3), 814-825 (2011). doi.org/10.3758/s13428-011-0091-y

13. D. Kardefelt-Winther, Computers in Human Behavior 38, 68-74 (2014). doi.org/10.1016/j.chb.2014.05.020

14. T. Hainey, T. Connolly, M. Stansfield, E. Boyle, Computers \& Education 57(4), $2197-$ 2211 (2011). doi.org/10.1016/j.compedu.2011.06.001

15. N. Yee, Cyber Psychology \& Behavior. 9(6), (2007) doi.org/10.1089/cpb.2006.9.772

16. M.C. Carras, A.J. Van Rooij, D. Van de Mheen, R. Musci, Q.L. Xue, T. Mendelson, Video gaming in a hyper connected world: A cross-sectional study of heavy gaming, problematic gaming symptoms, and online socializing in adolescents (Computers in Human Behavior, 2017) doi.org/10.1016/j.chb.2016.11.060

17. V.L. Malygin, Medical Psychology in Russia 6, (2011).

18. V.I. Morosanova, Individual style of self-regulation (Nauka, Moscow, 2001). 